\title{
Review
}

\section{DEVELOPMENT OF A MOBILE ROBOT FOR REMOTE MONITORING FOR MULTIMEDIA AND DATA ACQUISITION}

\author{
James AGAJ01, Ajao Lukman ADEWALE1, Okhaifoh JOSEPH ${ }^{2}$, Alao Emmanuel \\ OLAMIDE $^{1}$, Bolaji ABDULRAHMAN ${ }^{1}$
}

${ }^{1}$ Department of Computer Engineeering, Federal University of Technology, P.M.B 65, Minna, Nijerya

${ }^{2}$ Department of Electrical/Electronics, Federal University of Petroleum Effurun, P.M.B 1221 Delta State,

Nigeria

Received: April 26, 2020; Accepted: May 26, 2020; Published: July 01, 2020

\begin{abstract}
This research is based on the development of a mobile robot for remote monitoring and data acquisition. The project aims at improving the problem found in the available data acquisition systems. The available systems are stationary systems that make use of data loggers to store the acquired data and they also require human personnel to move the system from one place to another while some systems require that the user pay for an internet connection for storing the acquired data on the Internet. To eliminate these problems there is a need for a robot with the ability to move from one place to another, a robotic arm for taking readings from specific points and a direct RF connection for data acquisition. The robot makes use of four wheels for movement, three servos to achieve three degrees of freedom with a Wi-Fi camera and DHT11 sensor for real-time data acquisition. Data acquired from the sensor is been transferred wirelessly to the OLED display on the remote controller by the HC-11 RF transceiver module. From the results obtained, the robot has an average speed of $0.14 \mathrm{~m} / \mathrm{s}$ when carrying a payload of $1 \mathrm{Kg}$ and the accuracy of the robotic is $\pm 2 \stackrel{\circ}{\circ}$. The power consumed in the busy mode is quite remarkable with a difference of $650 \mathrm{~mW}$ as compared to the idle mode. Therefore, the system developed in this work will therefore reduce the risk posed to field agents since it does not require a supervisor on the monitored site. Also by replacing an online server for data logging by a wireless remote control interface with display, the cost of implementing the system was reduced.
\end{abstract}

Keywords: Mobile robot, Multimedia, Data acquisition, Remote monitoring

\footnotetext{
*Corresponding author: Department of Computer Engineeering, Federal University of Technology, P.M.B 65, Minna, Nijerya E mail: agajojul@gmail.com (J. AGAJO)

James AGAJO

(iD) https://orcid.org/0000-0001-5773-4249

Ajao Lukman ADEWALE

Okhaifoh JOSEPH

Alao Emmanuel OLAMIDE

Bolaji ABDULRAHMAN

(D) https://orcid.org/0000-0003-1255-752X

(iD) https://orcid.org/0000-0002-4558-7410

(iD) https://orcid.org/0000-0002-8790-3338

(D) https://orcid.org/0000-0002-3799-0912

Cite as: Agajo J, Adewale AL, Joseph O, Olamide AE, Abdulrahman B. 2020. Development of a mobile robot for remote monitoring for multimedia and data acquisition. BSJ Eng Sci, 3(3): 115-123.
} 


\section{Introduction}

These days, technology plays a very significant role in our day to day activities. For over half a century now, robotics has being a staple of Advance Manufacturing. Even though, underdeveloped and developing countries are really lacking behind in the field of robotics (Pooventhan et al., 2015), automated inventions that can behave in a similar way to a human have been recognized all through history. The majority of them were created for entertainment purposes. Fiction writers have found enormous success in writing about robots in diverse situations which imply that the robot was part of everyday conversation and imagination.

The term robot was first used in a Czech play called Rossum's Universal Robots (R.U.R), by Karl Capek in 1921. In the play a race of humanoid robots turned against their masters and destroyed them, this is an idea that is often always associated with robots. Still in today's technological age, the accurate definition of the word robot is a subject of debate. Most definitions of robot are rather broad and may possibly encompass any number of recent devices from a dishwasher, a timer-controlled compact disc play, an autonomous CCTV camera, to an Unmanned Aerial Vehicle (UAV).

A more precise definition of robot was stated by the Robot Institute of American that; "A robot is a programmable multifunctional manipulator designed to move materials, parts, tools or specialized devices through variable programmed motions for the performance of a variety of tasks". George Devol and Joseph Engelberger in 1956, created the world's first robot company. By the 1960s, robots were employed in the General Motors automobile plant in New Jersey for carrying car parts around. Robots have substituted humans in carrying out some task due to their sustained development. They are even used at homes as toys, vacuums cleaners, and as programmable pets, robots are now components of many aspects of industry, science, medicine, construction, space exploration, food packaging and are even used to carry out surgeries.(Pradnya et al., 2015)

Monitoring also called surveillance is the process of watching, observing, keeping track of, listening to, or checking (something) for a special purpose over a period of time (Agajo et al., 2012). Hence, monitoring may be applied to observations done from a distance by the use of electronic equipment (like CCTV cameras), or by intercepting electronically transmitted information (like phone calls or Internet traffic). This could also refer to relatively, simple no or low-technology methods such as postal interception and human intelligence agents (Agajo et al., 2012).

For this application, monitoring robots most have a camera as an analogy to the human eye for watching the monitored environment, sensors for measuring physical phenomenon and limbs in the form of actuators for reaching out to objects and for variable movements in remote areas (Devjyoti et al., 2015). The use of cameras mounted at a fixed point like the CCTV cameras is not that useful as the view of the camera cannot be adjusted in real time and obstructions like trees may block the view of the robot (Sivasoundari et al., 2015).

Manned monitoring missions are critical to acquiring useful intelligence, but sending human personnel into sensitive areas can often be too dangerous and may result in the loss of the precious life of field researchers. Furthermore, the available data acquisition systems are usually stationary systems with a data logger that requires human personnel to change the position of the system. The problem of such stationary monitoring systems is that the data acquired is not real time, it is just for a particular location since the system is immobile and there is the possibility of loss or corruption of the acquired data on the system by unforeseen environmental disasters like earthquake, flood and heavy wind storm or by the deliberate alteration of the acquired data by a third party.

Although some standalone data acquisition systems do exist, they always require that the systems connect to a server and dump the acquired data in a database. The problem with such system is that the user will have to pay an internet service provider (ISP) for a connection to the internet and in a developing country like ours such a system cannot be relied on due to the poor network experienced in remote areas. Furthermore, the user will have to use a secured virtual private network to ensure the confidentiality of the data acquired. That is why in this research work a direct radio frequency communication was employed between the user and the monitoring robot.

\section{System Methodology}

\subsection{System Overview}

The mobile robot is a device with the ability to move from one place to another through the use of rotating wheels. The system is made of wheels, a camera, sensors and robotic arm. The wheels will enable the robot to move around during the monitoring operation. This wheel is made of two tyres for forward and backward movement and two front tyres for direction that is left and right movement forming a system of four wheeled vehicle with a good balance. The robot is being powered by a $12 \mathrm{~V}$ DC battery with considerable amperage rating to operate the robot for a significant amount of time. (Ahmed et al., 2016).

The robot's wheels are controlled using a customized handheld remote control that uses Radio Frequency (RF) waves for communication. This enables the user to effortlessly control the movement of the robot around the monitored site. Robotic arm is used for picking objects on the ground or moving obstacles, this function is also controlled by the user. The camera installed on the robot provides a real-time video stream of the environment to the user while moving the robot around. 
All of these operations are coordinated by the Arduino microcontroller. The overall system block diagram is described in Figure 1.

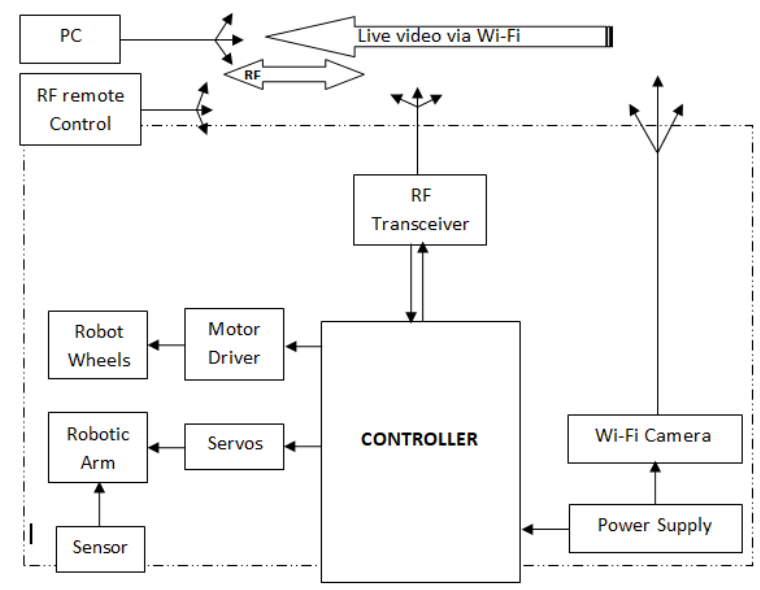

Figure 1. Overall block diagram for the Mobile Robot System for Data Acquisition.

\subsection{The System Objectives}

The key objective of the remote monitoring robot is to enable use of robots in performing various tasks that are very risky to human health. And the two obviously dangerous tasks known to man are monitoring and data acquisition especially in remote areas with harsh climatic conditions. Additionally, the robot will be able to receive instructions, and transmit the data it obtain in real time, thereby improving the reliability of data obtained since there is no middle man between the system and the researcher (user).

\subsection{System Flow Chart}

The various operation phases of the monitoring robot and it remote control interface is as shown in Figure 2.
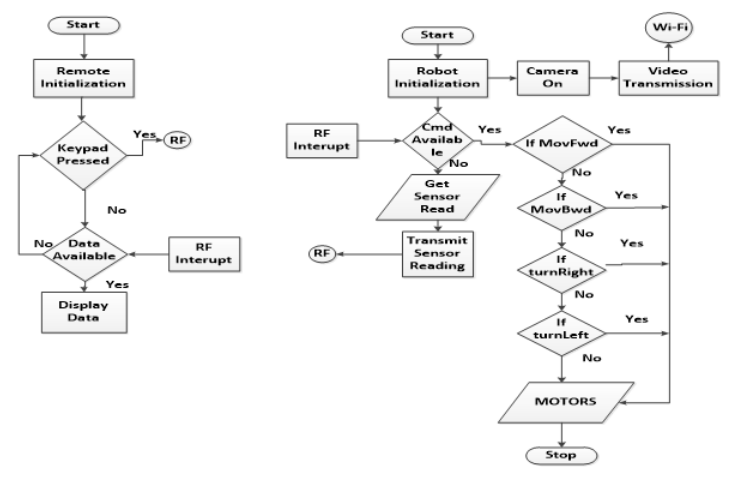

Figure 2. Monitoring robot flow chart

\subsection{System Hardware Design Considerations}

The system hardware section comprises of the various physical electronic and electromechanical components of the system. The hardware section comprises of two major subsystems: the robot body and the wireless remote control.

\subsection{Mobile Robot Unit}

Basically, the robot body is the actual field agent that moves around the monitored area, it receives instructions on the direction to follow from the remote control and also transmit the data it receives from the environment to the remote control interface. It is made up of the Power Supply Unit, Microcontroller Unit, Movement Unit, Transmission Unit, Video Streaming Unit, Sensor Unit and Robotic Arm Unit see schematic in Figure 3.

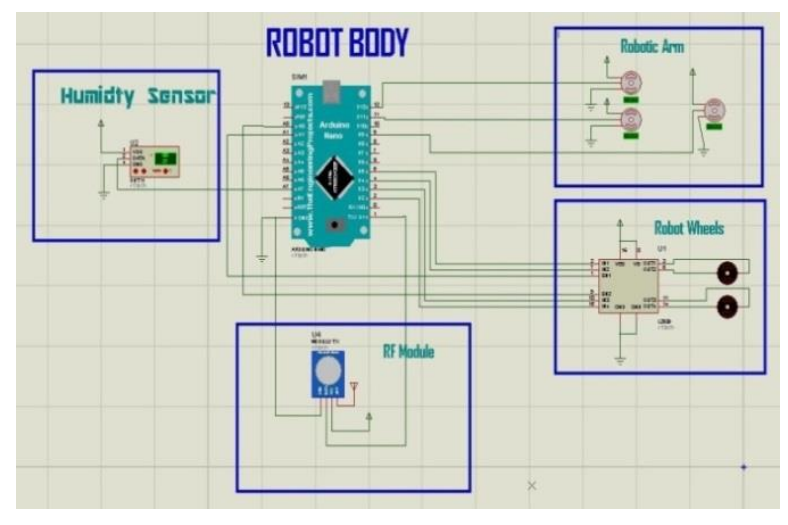

Figure 3. Circuit Diagram of the Robot Body

\subsection{Robot Power Supply Unit}

A DC to DC converter circuit is implemented where the $11.1 \mathrm{~V}$ from the lithium ion battery is passed through LM7807 linear voltage regulator which helps to drop the voltage to 7V for the servos and motors. A LM7805 linear voltage regulator is also connected to the battery to provide drop the constant $5 \mathrm{~V}$ for the DHT11 sensor and the motor driver. The DC port connected to the battery can be used to charge it directly using a $12 \mathrm{~V}$ DC power adapter.

An AC Power Supply Source is discarded in order to reduce the weight that will be added to the system through the use of an AC transformer which requires a smoothing stage and a voltage regulation and stabilization stage. (Anand and Vikram,2016)

\subsection{Movement Unit}

This unit provides mobility to the robot and therefore enables the robot to move from one place to another while monitoring the site. It comprises of the motor driver, two motors and four wheels. Two of the wheels are connected to one of the geared motor at the back of the robot for moving the robot forward and backward while the other two wheels are connected to the motor at the front for turning the robot to the left or right direction. These movements are all achieved with the help of the L293D motor driver being interfaced with the microcontroller. The speed of the robot was calculated using the following formula;

$\mathrm{V}=\mathrm{Eb}+\mathrm{IaRa}, \mathrm{V}$ is the supplied voltage,

$\mathrm{Eb}$ is the back EMF, Ia is the armature current of the 
Motor in the robot, Ra is the armature resistance.

\subsection{Arduino Microcontroller Unit}

In the heart of the mobile robot is the Arduino Nano, which is one of the many varieties of the Arduino microcontroller series. Arduino Nano is a compact, complete breadboard-friendly development board with is based on the ATmega328. It has similar functionalities to Arduino Uno since they make use of the same type of Atmega chip in Figure 4.

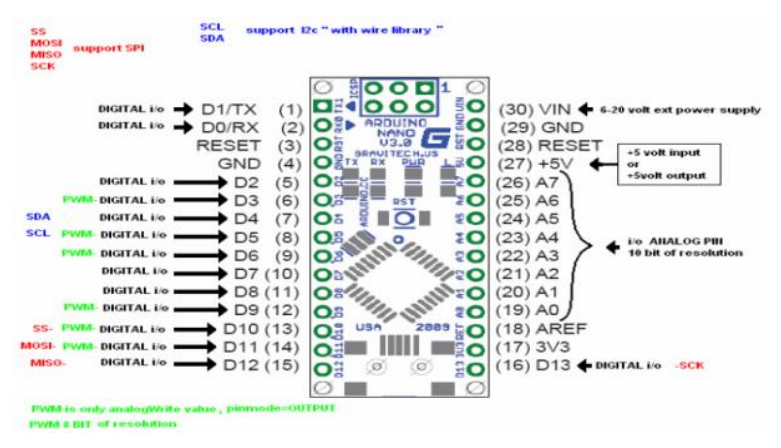

Figure 4. The remote monitoring robot microcontroller

\subsection{Transmission Unit}

Wireless communication between the robot body and the remote control is carried out by theHC11 RF transceiver module. The HC11 transceiver makes use of the Universal Asynchronous Receiver and Transmitter (UART) protocol at a baud rate of 9600 bits per seconds. It provides the medium for carrying the data from the mobile robot to the remote control interface and vice versa. The module was interfaced with the Arduino microcontroller and mounted on the body of the robot with the antenna pointing upwards (All on Robots, 2016).

\subsection{Sensor Unit}

The sensor unit is made up of the DHT11 sensor and WiFi camera. The Temperature and Humidity is acquired using the DHT11 sensor because of it stability. The sensor was interfaced with the microcontroller and the microcontroller is programmed such that the readings obtained from the sensor are transmitted wirelessly to the remote control which displays the values in real time. A live video stream of the environment being monitored is captured and transmitted using the onboard Wi-Fi camera. MD81 Wi-Fi camera was chosen because it works in a hotspot mode such that it serves as a wireless access point for the receiving device which could be a mobile phone, laptop or any other digital electronic device that support video streaming over Wi-Fi (Anand and Vikram ., 2016)

\subsection{Robotic Arm Unit}

The robotic arm is made of three servos connected in such a way that allow a rotational motion of the arm to enable the robot to pick or manipulate objects in the area being monitored. The linkage is as shown in Figure 5.

\subsection{Wireless Remote Controller Unit}

The wireless remote control is used to direct the robot and to also receive the data transmitted by the robot. When the robot is turned on it communicates with the remote control by transmitting the readings from the sensor to the remote control which in turn display the readings. The remote is made up of the Power Supply Unit, microcontroller Unit, push buttons Unit, Transmission Unit and the Display Unit.

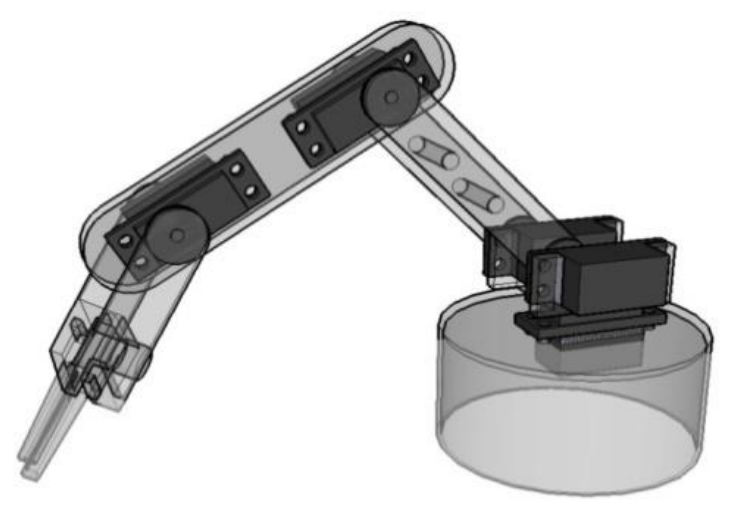

Figure 5. A robotic arm made of servo motors

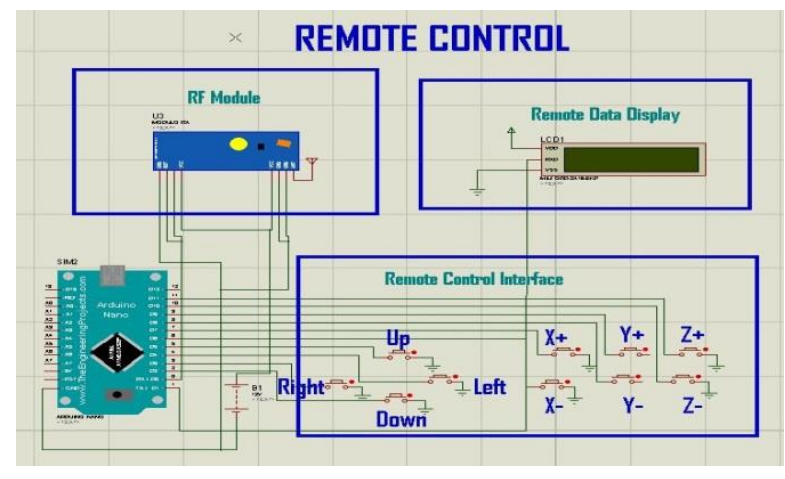

Figure 6. Circuit Diagram of the Wireless Remote Controller Unit

\subsection{Interfacing Servo Mechanism with Arduino}

Each of the servos require a pulse width modulated (PWM) signal to work and so they were all connected to PWM enabled pins of the Arduino. The first, second and third servo were connected to pin 9, pin 10 and pin 11 of the Arduino respectively. By so doing it becomes easy to move the arm from one position to another.

\subsection{Interfacing Geared DC Motors and Motor Driver to Arduino}

The geared DC motors were required for the robot to move from one place to another. The major challenge with interfacing these motors is that they cannot be powered directly by the Arduino microcontroller. This is because the Arduino can only supply a maximum voltage of $5 \mathrm{~V}$ and a current of $40 \mathrm{~mA}$ but the motors require minimum of $7 \mathrm{~V}$ and $100 \mathrm{~mA}$ current.

Therefore, to successful interface them together the L293D motor driver was connected between the Arduino board and the Geared motors. The Arduino pins 2, 3, 4 and 5 were connected to the L293D input pin 4, 3, 2 and 1 respectively. Then motor 1 was connected to output pin 
1 and 2 of the motor driver while motor 2 was connected to output pin 3 and 4 of the motor driver. Vss pin of the motor driver was connected to the battery supply voltage and the ground pin was connected to the battery's ground pin. The overall system circuit diagram is shown in Figure 7.

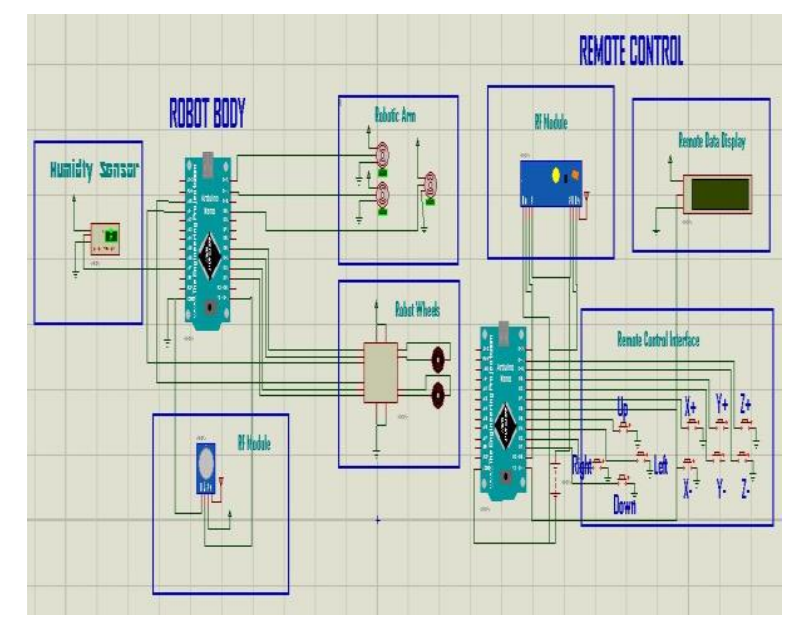

Figure 7. Monitoring Robot Overall System Circuit Diagram

\subsection{System Software Design Considerations}

The various units of the remote monitoring robot require a software program on the Arduino in order to coordinate their various operations. And so the system was first simulated before the actual implementation. The major software used is Proteus ISIS and the Arduino IDE. Proteus being a Virtual System Modeling and circuit simulation application was used to design and simulate the robot's circuitry. Arduino IDE is specifically designed for the Arduino microcontroller series, it makes it very easy to write programs and upload to the board.

\subsection{System Mathematical Model}

This section describes the mathematical calculations that were put into consideration during the selection of the actuators used. The major components of the robot that require mathematical consideration are the motors and the servo mechanism used in constructing the robotic arm. The motors and servos were selected base on the result obtained as shown below.

\subsection{Robotic Arm Inverse Kinematics}

This is the process of calculating the joint angles, in order to obtain a desired position. The angles and direction of the end effector can be obtained from the following mathematical equation.

From Figure 9, using cosine rule and Pythagoras theorem we get;

$\left(x^{2}+y^{2}\right)=l_{1}^{2}+l_{2}^{2}+2 l_{1}^{2} l_{2}^{2} \cos (180-\beta)$

Since $\cos \left(180-\theta_{2}\right)=-\cos (\alpha)$

Where $\beta$ is the angle between the shoulder and elbow servo motor, $\alpha$ is the angle between the elbow servo and the end effector,

$\gamma$ is the angle between the base and the shoulder servo motor. Then equation (1) becomes

$\left(x^{2}+y^{2}\right)=l_{1}^{2}+l_{2}^{2}-2 l_{1}^{2} l_{2}^{2} \cos (\beta)$

$\cos \beta=\frac{x^{2}+y^{2}-l_{1}^{2}-l_{2}^{2}}{2 l_{1} l_{2}}$

Hence, $\beta=\cos ^{-1} \frac{x^{2}+y^{2}-l_{1}^{2}-l_{2}^{2}}{2 l_{1} l_{2}}$

From the Figure 9,

$\frac{\sin \alpha}{l_{2}}=\frac{\sin \phi}{x^{2}+y^{2}}$

$\theta=\tan ^{-1} \frac{y}{x}$

But $\sin \phi=\sin (180-\beta)=\sin \beta$

$\alpha=\sin ^{-1}\left[\frac{l_{2} \sin \phi}{\sqrt{x^{2}+y^{2}}}\right]$

$\alpha=\sin ^{-1}\left[\frac{l_{2} \sin \beta}{\sqrt{x^{2}+y^{2}}}\right]$

$\gamma=\alpha+\theta$

Then $\gamma$ can be expressed as

$\gamma=\sin ^{-1}\left[\frac{l_{2} \sin \beta}{\sqrt{x^{2}+y^{2}}}\right]+\tan ^{-1} \frac{y}{x}$

Therefore the required angle for the base servo motor, second and third degree servo motor are $\theta_{0}, \theta_{1}$ and $\theta_{2}$ respectively.

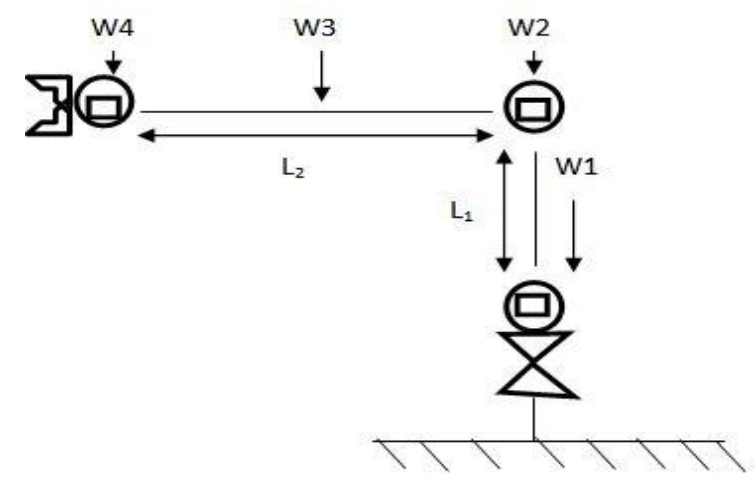

Figure 8. Robotic Arm Free Body Diagram.

\subsection{Robot Arm Degree of Freedom}

Robot arm degree of freedom is very important since the robot will be used in place of a human hand for taking measurements of specific points and for picking and placing objects. That why the robot has four degree of freedom. The four degree of freedom of the robot is as shown in Figure 10.

First Degree: is the movement of the base of the robot 
which is equivalent to the movement of the human waist. Second Degree: is the up and down movement of the robot arm servo which is similar to the movement of a human shoulder. Third Degree: is the forward and backward movement of the robot arm as compared to the human elbow. Fourth Degree: is the open and close movement of the grippers similar to the movement of the human fingers.

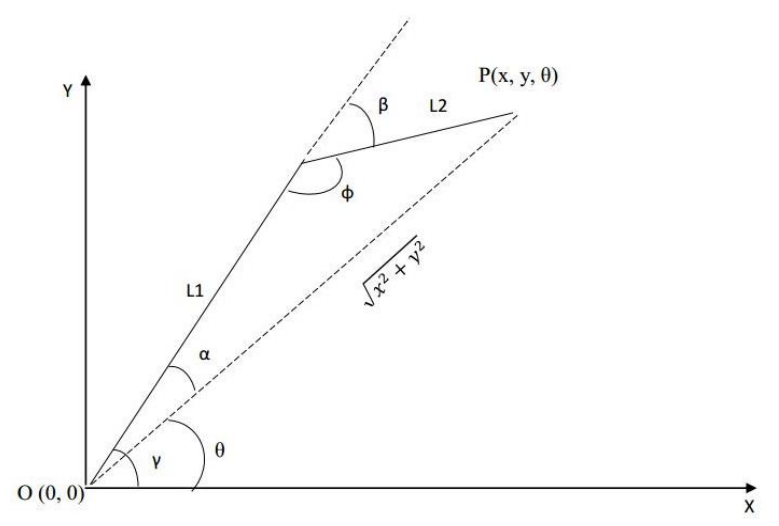

Figure 9. Robotics arm on X Y plane

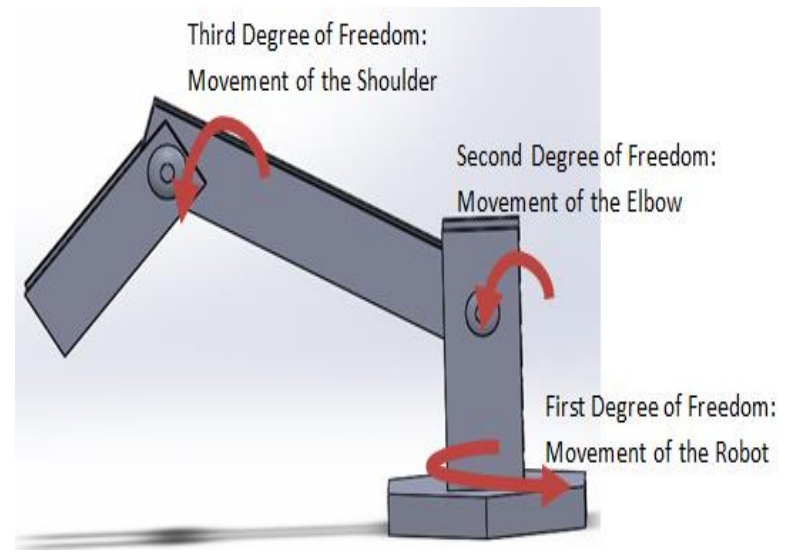

Figure 10. Robot arm degree of freedom

\subsection{Hardware Development on Vero Board}

As stated earlier the system was first designed and simulated using Proteus ISIS software. Although, the simulation was successful, it is not enough to conclude on the behavior of the system. To do this, the various part of the system were first assembled and tested on a breadboard before soldering on the Vero board. The developed hardware is shown in Figure 11.

\subsection{Performance Evaluation}

The performance metrics used in this project is latency, cost of implementation and power consumption. The primary goal of presenting the latency of the video stream transmitted from the camera, the overall power consumption and cost of implementation is to help future researchers to wisely select their components and methodology.

\subsection{Camera Latency}

To calculate the latency of the video stream, the camera was powered and the software used for displaying the video stream was used to record the bits per seconds of the transmission and the frame rate while varying the robot position.

\subsection{Power Consumption}

As a remote monitoring robot the performance is greatly influenced by the power consumed by the system since it determine how long the system can perform it duty of monitoring and data acquisition. The result obtained for the system idle mode and busy was recorded. The idle mode is a situation where the system is working like the conventional stationary system while the busy mode is the situation where the system is fully functional.

Known: Battery Voltage, V=7volt

power, $\mathrm{P}=7 * \mathrm{I}$ (current)

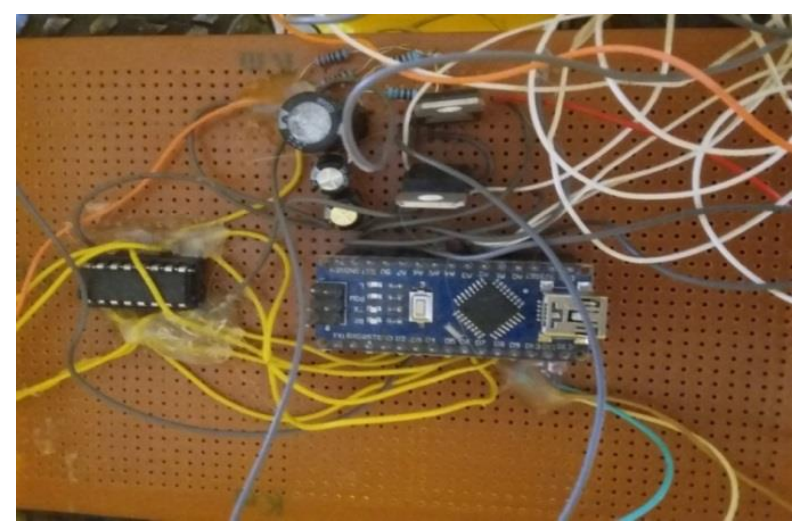

Figure 11. Robot connection on vero board

\section{Testing Result}

After designing and simulating the system using Proteus ISIS simulation software the connections were then tested on a breadboard to ensure the system behavior is as expect before soldering the components onto the Vero board. The final packaging of the robot body, the remote control and the video stream from the camera is shown in Figures 12, 13 and 14.

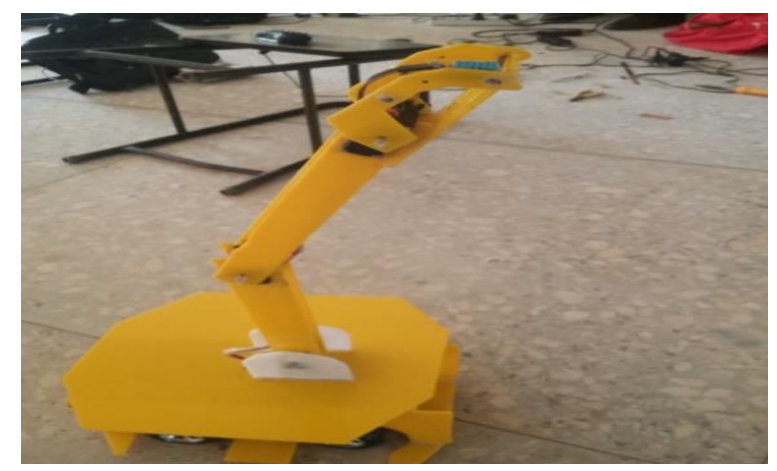

Figure 12. Robot body during testing 


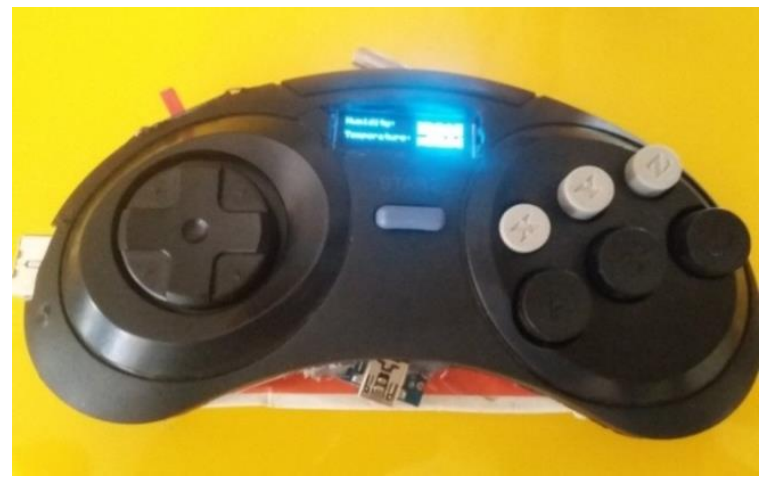

Figure 13. Remote control during testing

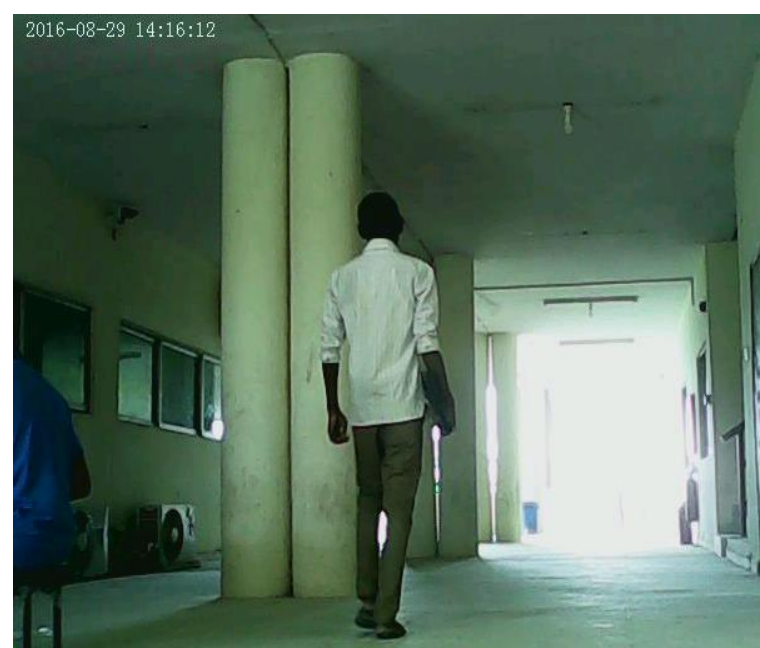

Figure 14. Video stream from the camera during testing

Various tests were carried out on the system to ensure the system was functioning as expected. The microcontroller output pins were first tested by running sample codes to ensure that the digital pins are able to perform the desired input and output function.

\subsection{Robot Speed}

The speed of the robot was tested base on the amount of weights that were added to the system in view of the fact that the speed of the robot is inversely proportion to the weight. Table 1 shows the result of adding a weight of $0.1-2 \mathrm{Kg}$ to the system. Robots speed test was carried out over a distance of 10 meters, the time taken by the robot was obtained using a stop watch and recorded as shown in Table 1, Figure 15 also gives a graphical representation of the data obtained and the resulting speed was calculated using the speed equation in section 3.

\subsection{Robot Arm Position}

The degree of accuracy of the robotic arm is also very important since it determines how correctly the system can acquire data at strategic points. The higher the accuracy the more reliable the data obtained. This is because the system is expected to be able to change the position of the arm as quickly as possible while taking readings. The arm position was tested by writing different pulse width modulation signals to the servo from $0^{\circ}$ through $180^{\circ}$. A mark was placed on the servo arm which was used to observe and record the deviation of the arm from the expected angle and then used to recalibrate the servos. The results obtained are shown in Table 2, 3 and 4 .

Table 1. Robot speed test

\begin{tabular}{cccc}
\hline $\begin{array}{c}\text { Weight } \\
\text { (gram) }\end{array}$ & $\begin{array}{c}\text { Distance } \\
(\mathrm{m})\end{array}$ & $\begin{array}{c}\text { Time } \\
(\mathrm{s})\end{array}$ & $\begin{array}{c}\text { Motor Speed } \\
(\mathrm{m} / \mathrm{s})\end{array}$ \\
\hline 100 & 10 & 40 & 0.25 \\
200 & 10 & 44 & 0.22 \\
400 & 10 & 50 & 0.20 \\
600 & 10 & 56 & 0.18 \\
800 & 10 & 62 & 0.16 \\
1000 & 10 & 70 & 0.14 \\
1200 & 10 & 77 & 0.13 \\
1400 & 10 & 83 & 0.12 \\
1600 & 10 & 92 & 0.11 \\
1800 & 10 & 103 & 0.10 \\
2000 & 10 & 102 & 0.08 \\
\hline
\end{tabular}

Table 2. Shoulder joint

\begin{tabular}{|c|c|c|c|c|}
\hline $\begin{array}{l}\text { Test } \\
\text { S/N }\end{array}$ & $\begin{array}{l}\text { Expected } \\
\text { E }(\stackrel{\circ}{)})\end{array}$ & $\begin{array}{c}\text { Actual } \\
\text { Angle A } \\
(\underline{o})\end{array}$ & $\begin{array}{c}\text { Deviation } \\
\mathrm{D}=\mathrm{A}-\mathrm{E} \\
(\underline{\mathrm{o}})\end{array}$ & $\begin{array}{c}\text { Error } \\
E=D / E \\
(\%)\end{array}$ \\
\hline 1 & 0 & 0 & 0 & 0 \\
\hline 2 & 15 & 13 & -2 & -13.33 \\
\hline 3 & 30 & 31 & 1 & 3.33 \\
\hline 4 & 45 & 46 & 1 & 2.22 \\
\hline 5 & 60 & 58 & -2 & -3.33 \\
\hline 6 & 90 & 92 & 2 & 2.22 \\
\hline 7 & 135 & 134 & -1 & -0.74 \\
\hline 8 & 180 & 181 & 1 & 0.56 \\
\hline
\end{tabular}

Table 3. Elbow joint

\begin{tabular}{|c|c|c|c|c|}
\hline $\begin{array}{l}\text { Test } \\
\text { S/N }\end{array}$ & $\begin{array}{l}\text { Expected } \\
\qquad E(\underline{o})\end{array}$ & $\begin{array}{c}\text { Actual } \\
\text { Angle A } \\
(\underline{o})\end{array}$ & $\begin{array}{c}\text { Deviation } \\
\text { A-E }(\stackrel{o}{)})\end{array}$ & $\begin{array}{c}\text { Error } \\
E=D / E \\
(\%)\end{array}$ \\
\hline 1 & 0 & 0 & 0 & 0 \\
\hline 2 & 15 & 14 & -1 & -6.67 \\
\hline 3 & 30 & 32 & 2 & 6.67 \\
\hline 4 & 45 & 43 & -2 & -4.44 \\
\hline 5 & 60 & 58 & -2 & -3.33 \\
\hline 6 & 90 & 91 & 1 & 1.11 \\
\hline 7 & 135 & 134 & -1 & -0.74 \\
\hline 8 & 180 & 179 & -1 & -0.56 \\
\hline
\end{tabular}

Table 4. Gripper

\begin{tabular}{|c|c|c|c|c|}
\hline $\begin{array}{l}\text { Test } \\
\mathrm{S} / \mathrm{N}\end{array}$ & $\begin{array}{c}\text { Expected } \\
\text { E }(\stackrel{\circ}{)})\end{array}$ & $\begin{array}{l}\text { Actual } \\
\text { Angle } \\
\text { A }\left(\underline{o}^{\circ}\right)\end{array}$ & $\begin{array}{c}\text { Deviation } \\
\text { A-E }(\stackrel{\circ}{)})\end{array}$ & $\begin{array}{c}\text { Error } \\
\mathrm{E}=\mathrm{D} / \mathrm{E} \\
(\%)\end{array}$ \\
\hline 1 & 0 & 0 & 0 & 0 \\
\hline 2 & 15 & 17 & 2 & 13.33 \\
\hline 3 & 30 & 31 & 1 & 3.33 \\
\hline 4 & 45 & 44 & -1 & -2.22 \\
\hline 5 & 60 & 58 & 2 & 3.33 \\
\hline 6 & 90 & 89 & -1 & -1.11 \\
\hline 7 & 135 & 133 & -2 & -1.48 \\
\hline 8 & 180 & 178 & 2 & 1.11 \\
\hline
\end{tabular}


Black Sea Journal of Engineering and Science

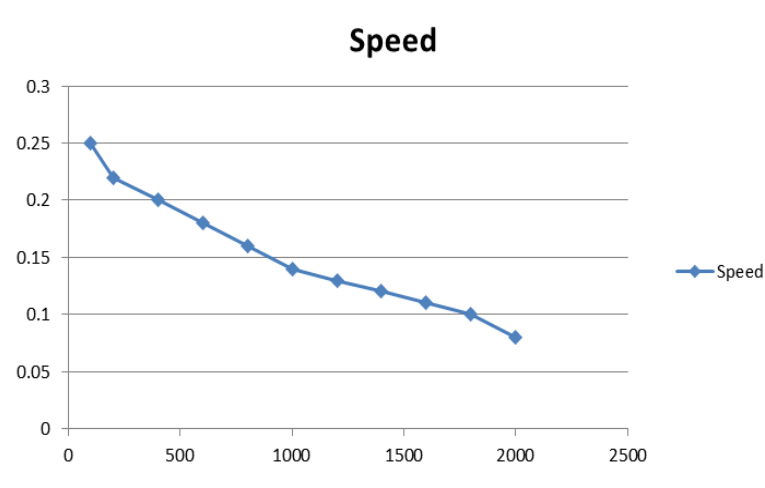

Figure 15. Graph showing the speed with respect to added weight

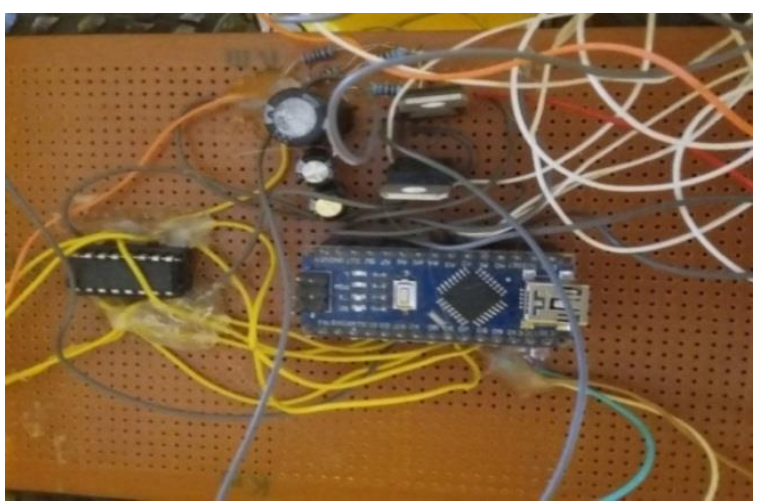

Figure 16. Graph showing the speed with respect to added weight

\section{3. Performance Evaluation}

The performance of the system was evaluated base on the latency, cost of implementation and power consumption.

\section{4. Camera Latency}

Figure 4 presents the graphical view of the recorded values for speed of the video stream obtained from the camera at various distances from the robot.

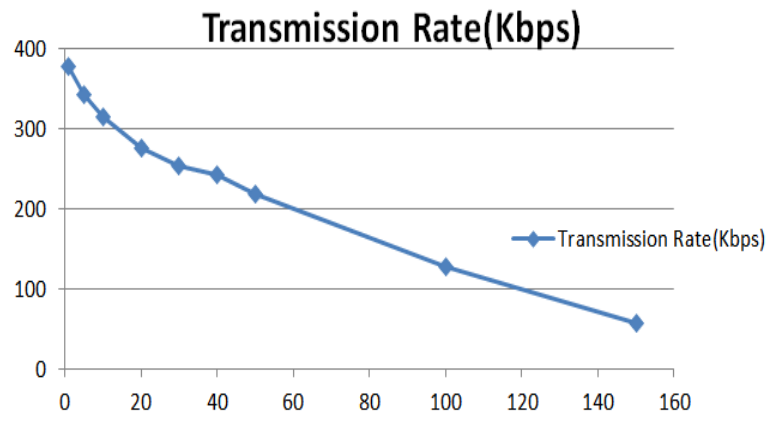

Figure 17. Graph showing transmission rate with respect to Distance

\subsection{Power Consumption}

Table 5 shows the result obtained when robotic system is in the idle mode and busy mode after performing five (5) different tests.
Table 5. Power consumption

\begin{tabular}{ccccc}
\hline $\begin{array}{c}\text { Test } \\
\text { S/N }\end{array}$ & \multicolumn{2}{c}{$\begin{array}{c}\text { Idle Mode I }(\mathrm{mA}) \\
\text { Power }(\mathrm{mW})\end{array}$} & \multicolumn{2}{c}{$\begin{array}{c}\text { Busy Mode I }(\mathrm{mA}) \\
\text { Power }(\mathrm{mW})\end{array}$} \\
\hline 1 & 110 & 770 & 850 & 5950 \\
2 & 103 & 721 & 770 & 5390 \\
3 & 115 & 805 & 820 & 5740 \\
4 & 108 & 756 & 830 & 5810 \\
5 & 105 & 735 & 795 & 5565 \\
\hline
\end{tabular}

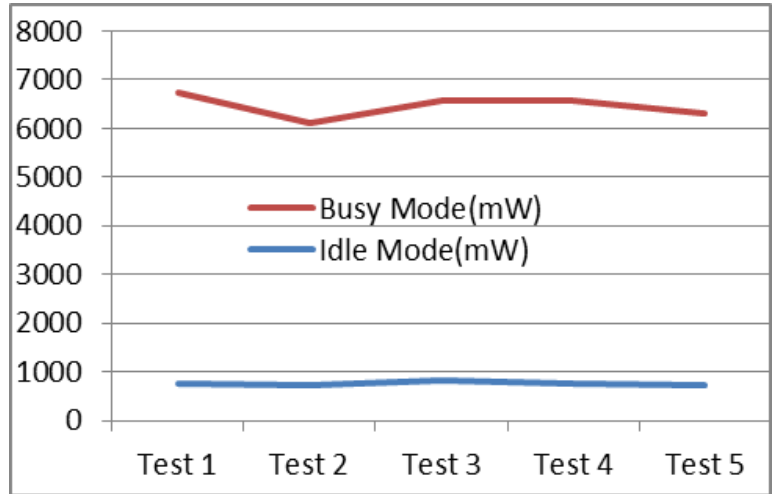

Figure 18. Graph showing power consumed with respect to the system mode

\subsection{Discussion of Result}

The result obtained in the robot speed test as shown in Table 1, shows that the average speed of the robot as regard to the weight of the payload is 0.14 meters per second. This is equivalent to 900 meters per hour which is very reasonable since the robot is not really expected to move too fast while taking readings. Figure 15 shows that the speed of the robot decreases with the weight. From Table 2, 3 and 4 it can be clearly observed that there were deviations of each of the servo arm from the expected position. The three servos have an average error of $\pm 2^{\circ}$ or $\pm 13.33 \%$, but by calibrating the servos from the programming code, the error was reduced to $\pm 1^{\circ}$. By so doing the accuracy of the robotic arm position was improved for acquiring data at a specific position.

The transmission rate of the camera is $200 \mathrm{Kbps}$ at about 60 meters from the camera as shown in Figure 14. At this transmission rate the video stream is quite commendable with 15 frames per second. Though, the transmission rate of the camera can be improved by using a wireless repeater to reproduce the signal and boost the range of the transmission.

The power consumed by the system in the idle mode is very low as compared to the power consumed in the busy mode which is as expected because in the idle mode the robotic wheels and the servos were not in use and they both consume a lot of current. The wheels consume an average of $100 \mathrm{~mA}$ each making a total of $200 \mathrm{~mA}$ for the two motors, while the servo motors used consumes an average of $150 \mathrm{~mA}$ each making a total value of $450 \mathrm{~mA}$. So there is an average difference of $650 \mathrm{~mA}$ current consumption as shown in Figure 18. 


\section{CONCLUSION}

It apparent that monitoring and data acquisition are very important factors in our day to day activities. Therefore, the mobile robot for remote monitoring and data acquisition developed in this project will help to improve the availability and reliability of quality data and most importantly, it will help to reduce the risk to the life of field agents or researchers.

Therefore the aim of this project which is to develop a mobile robot for remote monitoring and data acquisition has been achieved. And from the result obtained it can be concluded that the system is efficient, reliable and $\cos 1 t$ effective.

\subsection{Recommendations and Future Works}

The following are recommended for future works on the design of a mobile robot for remote monitoring and data acquisition;

- The range of the video stream transmitted can be increased by connecting the camera to the internet which implies that the video can be accessed anywhere in the world.

- The robot wheel could be upgraded to more powerful wheels to improve the mobility and tolerance of the system in rough terrains.

- Servos with more power and torque can be used in order to increase the maximum load that can be lifted by the robotic arm.

\section{Conflict of interest}

The authors declare that there is no conflict of interest.

\section{References}

Agajo J, Chukwujekwu OB, Awolo CI, Micheal IO. 2015. Efficient routing technique in a wireless sensor network using personal area network and artificial neural method. Inter J Electron Telecom Syst Res Electroscope J, 7(2), 7-13.

Agajo J, Theophilus AL, Idigo VE, Apkado KI. 2012. Optimization of network performance in wireless communication network. Pacific J Sci Technol University of Akamai Hawaii (USA), pp334-350.

All on Robots. 2016. Types of robot. http://www.allonrobots.com/types-of-robots.html (accessed date April 03, 2016).

Brain M. 2015. How radio works. How Stuffs Works.com, http://electronics.howstuffworks.com/radio8.html (accessed date April 03, 2016).

Gadve PG, Bais GN, Dhadge PJ, Jawalkar PB. 2015. Robot control design using android application for surveillance. Inter Engin Res J, 1(9): 960-963.

Ghosh D, Sahanie S, Bhandari S, Shirali V, Kapoor M. 2015. Web controlled surveillance robot. Inter J Emerg Technol Advance Engin, 5(10): 87-91.

Haidar AMA, Benachaiba C, Zahir M. 2013. Software interfacing of servo motor with microcontroller. J Electrical Syst, 9(1): 8499.

Joseph O, Nana UE, Agajo AKJ. 2013. Modelling high resolution radar system modeling with Matlab. Simulink, 1(1): 41-56.

Kolo JG, Folorunso SASTA, Agajo J, Abraham US. 2015. Compression Scheme for Wireless Sensor Network. Nigeria J Engin Appl Sci, 2(1): 143-154.

Nayyar A, Puri V. 2016. A comprehensive review of beagle bone technology: Smart board powered by ARM. Inter J Smart Home, 10(4): 95-108.

Pooventhan K, Achuthaperumal R, Kowshik S, Manoj Balajee C R. 2015. Surveillance robot using multi sensor network. Inter J Innov Res Electrical, Electronics, Instrument Control Engin, 3(2): 113-115.

Sandeep K, Srinath K, Koduri R. 2012. Surveillance security robot with automatic patrolling vehicle. Inter J Engin Sci Advance Technol, 2(3): 546-549.

Sivasoundari A, Kalaimani S, Balamurugan M. 2013. Wireless surveillance robot with motion detection and live video transmission. Inter J Emer Sci Engin, 1(6): 14-22. 